\title{
Self-Esteem's Moderation of Self-Congruity Effects on Brand Loyalty
}

\author{
Jane Brannen"1, Cynthia M. Frisby² \\ ${ }^{1}$ Young \& Laramore, Indianapolis, IN, USA \\ ${ }^{2}$ Department of Strategic Communication, University of Missouri, Columbia, MI, USA \\ Email: FrisbyC@missouri.edu
}

How to cite this paper: Brannen, J. and Frisby, C.M. (2017) Self-Esteem's Moderation of Self-Congruity Effects on Brand Loyalty. Theoretical Economics Letters, 7, 1848-1864.

https://doi.org/10.4236/tel.2017.76126

Received: August 1, 2017

Accepted: October 28, 2017

Published: October 31, 2017

Copyright ( 92017 by authors and Scientific Research Publishing Inc. This work is licensed under the Creative Commons Attribution International License (CC BY 4.0).

http://creativecommons.org/licenses/by/4.0/

(c) (i) Open Access

\begin{abstract}
This research set out to find how consumer self-esteem moderates the relative importance of actual self-congruity vs. ideal self-congruity on women's brand loyalty to fitness brands. College-aged women were the primary focus for this research because this demography represents an emerging consumer group and because the literature suggests women score significantly lower than men on self-esteem scales in physical appearance, athletic self, personal self, and self-satisfaction self-esteem. A survey of 151 women of $18-24$ ages was conducted supporting prior research findings that actual and ideal self-congruity are both positively correlated with brand loyalty.
\end{abstract}

\section{Keywords}

Consumer Self-Esteem, Actual Self-Congruity vs. Ideal Self-Congruity, Brand Loyalty, Gender Differences in Brand Loyalty, Moderating Effect of Self-Esteem and Brand Loyalty

\section{Introduction}

Self-congruity refers to the perceived degree of affinity between individual self-concept and a brand's perceptions [1]. Research has generally suggested that ideal self-congruity (that is, congruity between a brand and an individual's ideal self-concept) has a greater influence than actual self-congruity (that is, congruity between a brand and an individual's actual self-concept) on consumer behavior [2] [3]. However, Landon [4] found while ideal self-congruity has a greater effect than actual self-congruity for some consumers, actual self-congruity has the greater effect for others. And Malär, Krohmer, Hoyer, \& Nyffenegger [5] demonstrated that actual self-congruity has a greater effect on brand attachment than ideal self-congruity and that high self-esteem strengthens the relationship 
between actual self-congruity and emotional brand attachment. The researchers note an increasing interest in the effects of actual self-congruity and point to the success of the recent Dove Real Beauty campaign (which used realistic, rather than idealized, depictions of women's bodies to sell personal hygiene products).

More research into the effects of actual self-congruity on consumers' perception of and behavior toward brands is merited. The current study examines how consumer's self-esteem moderates the relative importance of actual self-congruity vs. ideal self-congruity on women's brand loyalty to fitness brands. Given Malär et al.'s [5] findings and research which suggests that individuals with high self-esteem are more difficult to persuade [6] [7], it may be that actual self-congruity has a stronger effect on brand loyalty for consumers with high self-esteem than for consumers with low self-esteem.

This research is of practical relevance to brand managers. Along with emotional brand attitude, consumer brand loyalty is one of the popular predictors of behavior toward a brand [8]. Studying self-esteem's influence on self-congruity motives and brand loyalty will help brand managers better understand and influence consumer behavior. In particular, this research focuses on the fitness market, in which self-esteem and self-concept are relevant concepts.

\section{Ease of Use}

Researchers have operationally defined the term "self-congruity" in various ways. All involve measuring similarity between some aspect of a brand and individual self-concept. Self-congruity can mean similarity between consumer self-concept and the symbolic meaning of the product itself [9] [10] [11], similarity between consumer self-concept and the brand personality or brand-as-person [1] [3], or similarity between consumer self-concept and the stereotypical product-user image [12] [13].

Because this research focuses on brand management, rather than product categories themselves, brand personality or stereotypical product-user image studies are more appropriate and relevant than product image studies. Of these two, more theoretical support has been provided for stereotypical product-user image studies. For example, Aguirre-Rodriguez et al.'s [2] meta-analysis found that "brand-as-person" evaluations showed a stronger self-congruity effect than stereotypical product-user image evaluations; however, Fang, Li, Mizerski and Soh [8] note that self-congruity patterns found in brand-as-person studies may be exaggerated because in the majority of these studies, brand personality congruity is the only independent variable and therefore its effect may be partially accounted for by other variables not studied. Additionally, Helgeson and Supphellen [3] found that self-congruity and brand personality are empirically discriminant and affect brand attitudes independently of each other. This suggests that the two concepts are not equivalent and studies which measure self-congruity defined as brand personality or brand-as-person may be conflating the two concepts.

Sirgy (arguably the foremost expert on self-congruity) chooses congruence 
between consumer self-concept and stereotypical product-user image [13]. Thus, this study will use the operationalization of self-congruity as perceived similarity between consumer self-concept and stereotypical product-user image both for the conceptual validity of this definition and for its simplicity.

Self-Congruity Motives. Sirgy's [14] four-part schema includes the following dimensions: actual self-concept, ideal self-concept, social self-concept and ideal social self-concept [14]. Each of these self-concept dimensions corresponds to a self-congruity motive: self-consistency motive for actual self-concept, social consistency motive for social self-concept, self-enhancement motive for ideal self-concept and social approval motive for ideal social self concept [2].

Actual vs. Ideal Congruity. Aaker [15] explains that the self-consistency motive (actual) and the self-enhancement motive (ideal) are driven by two distinct needs: consistency and positivity. Consumers' self-concepts are typically valenced positively, and the need for positivity motivates consumers to express these positive personality traits while the need for consistency motivates consumers to seek feedback consistent with their self-concepts, even if it is negatively valenced [15]. The social consistency motive and the self-enhancement motive are sometimes at odds.

Early research noted a gap of information on the relative influence of actual and ideal self-concept. Ross [16] and Dolich [10] argued that ideal self-congruity would matter more for socially conspicuous products than for privately consumed products, but Dolich [10] failed to find evidence that the self-enhancement motive was stronger than the self-consistency motive in any particular product category. Research conducted since then has provided more insight, and in 2012, Aguirre-Rodriguez et al.'s meta-analysis of degree of self-enhancement sought, which refers to how strongly an individual is influenced by actual self-motives (self-consistency and social consistency) vs. ideal self-motives (self-enhancement vs. social approval), found that enhancement-type motives have a stronger effect on consumer behavior than consistency-type motives.

However, Malär et al. [5] demonstrated that actual self-congruence has a greater effect on brand attachment than ideal self-congruence and note an increasing interest in the effects of actual self-congruity (Figure 1), and Graeff [17] found that there was no statistically significant difference between the effects of actual and ideal self-congruity on brand evaluations. In a study of perceived congruity with sports teams, Kwak and Kang [18] found that both actual congruity and ideal congruity explained a significant portion of variance in attendance frequency, media consumption and team loyalty but that actual congruity explained more of the variance for attendance frequency and media consumption. More research on the moderating influences that affect the importance of ideal self-congruence vs. actual self-congruence is merited.

\subsection{Self-Congruity Motives}

Sirgy's four-part schema includes the following dimensions: actual self-concept, ideal self-concept, social self-concept and ideal social self-concept [14]. Each of 
Malär et al.'s (2011) Framework Linking Self-Congruence to Emotional Brand Attachment

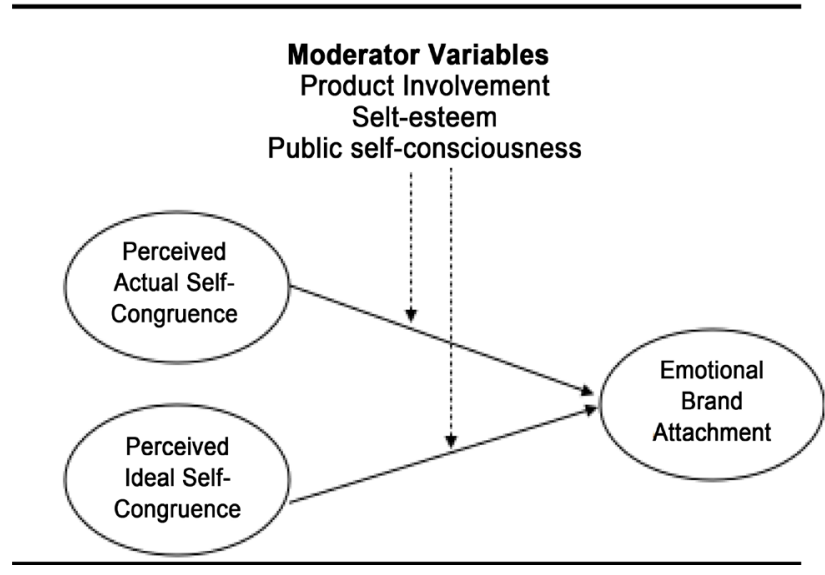

Proposed Framework Linking Self-Congruence to Brand Loyalty

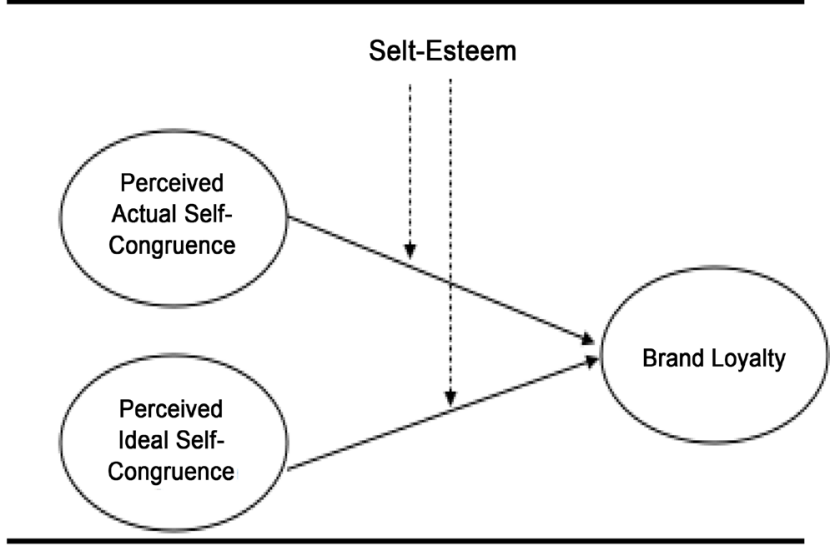

Figure 1. Self-Congruence Framework.

these self-concept dimensions corresponds to a self-congruity motive: self-consistency motive for actual self-concept, social consistency motive for social self-concept, self-enhancement motive for ideal self-concept and social approval motive for ideal social self concept [2].

Actual vs. ideal congruity. [15] explains that the self-consistency motive (actual) and the self-enhancement motive (ideal) are driven by two distinct needs: consistency and positivity. Consumers' self-concepts are typically valenced positively, and the need for positivity motivates consumers to express these positive personality traits while the need for consistency motivates consumers to seek feedback consistent with their self-concepts, even if it is negatively valenced [15]. The social consistency motive and the self-enhancement motive are sometimes at odds.

Early research noted a gap of information on the relative influence of actual and ideal self-concept. Ross [16] and Dolich [10] argued that ideal self-congruity would matter more for socially conspicuous products than for privately consumed products, but Dolich [10] failed to find evidence that the self-enhancement motive was stronger than the self-consistency motive in any particular product category. Research conducted since then has provided more insight, and in 2012, Aguirre-Rodriguez et al.'s meta-analysis of degree of self-enhancement sought, which refers to how strongly an individual is influenced by actual self-motives (self-consistency and social consistency) vs. ideal self-motives (self-enhancement vs. social approval), found that enhancement-type motives have a stronger effect on consumer behavior than consistency-type motives.

However, Malär et al. [5] demonstrated that actual self-congruence has a greater effect on brand attachment than ideal self-congruence and note an increasing interest in the effects of actual self-congruity, and Graeff [17] found that there was no statistically significant difference between the effects of actual and ideal self-congruity on brand evaluations. In a study of perceived congruity with sports teams, Kwak and Kang [18] found that both actual congruity and ideal 
congruity explained a significant portion of variance in attendance frequency, media consumption and team loyalty but that actual congruity explained more of the variance for attendance frequency and media consumption. More research on the moderating influences that affect the importance of ideal self-congruence vs. actual self-congruence is merited.

\subsection{Moderating Effects}

Individual differences. Individual differences may be important in this discussion. Landon [4] found that while overall purchases tended to correlate more with actual self-image than with ideal self-image, some subjects (Landon calls them "actualizers") tended to purchase items more correlated with their actual self-concept and others ("perfectionists") tended to purchase items more correlated with their ideal self-concepts. Malär et al's [5] research suggests that product involvement, self-esteem and public self-consciousness are among the characteristics that distinguish between actualizers and perfectionists. They found that for consumers with high self-esteem, high product involvement and/or high public self-consciousness, actual self-congruence had a stronger positive effect on emotional brand attachment.

Additionally, Aaker [15] found that self-congruity motives influence brand preference more for low self-monitoring individuals (whose behavior tends to be more consistent across varying social situations) whereas situational congruity motives influence brand preference more for high self-monitoring individuals (whose behavior tends to change according to the social situation). And Graeff [17] found that for publicly consumed items, self-monitoring had a significant moderating effect on the relationships between brand evaluations and actual self-congruity and between brand evaluations and ideal self-congruity but that for privately consumed products, self-monitoring did not have a significant moderating effect on either relationship.

Sung, Choi and Pinkham [19] found that brand preference was more strongly influenced by situational cues for consumers with interdependent self-construals (emphasizing relationships and flexibility) than for than individuals with independent self-construals (emphasizing autonomy and assertiveness).

Product conspicuousness. Dolich [10] found that self-congruity has a different effect on brand preference for socially consumed vs. privately consumed products, and Graeff [17] found that ideal self-congruity is more highly correlated than actual self-congruity to brand evaluations of publicly consumed brands but that there is no significant difference between the influences of actual and ideal self-congruity on brand evaluations of privately consumed brands.

\subsection{Expected Results}

Because self-congruity has a positive effect on brand preference [20], brand attitude [21] and brand loyalty [1], it is expected that both actual self-congruity and ideal self-congruity will both have a significant positive correlation with brand 
loyalty. Therefore, it is hypothesized that:

H1: Actual self-congruity will be positively correlated with brand loyalty.

H2: Ideal self-congruity will be positively correlated with brand loyalty.

Self-esteem is thought to be related to an individual's readiness to be persuaded [6] [7]. Additionally, brand attachment and brand loyalty are related concepts, and Malär et al. [5] found that the influence of actual self-congruence on emotional brand attachment is greater for consumers with high self-esteem and for those with low self-esteem.Taken together, this literature led to the development of hypotheses $3 \mathrm{a}$ and $3 \mathrm{~b}$ :

H3a: For participants with high self-esteem, actual self-congruity will have a stronger correlation with brand loyalty than ideal self-congruity.

H3b: For participants with low self-esteem, ideal self-congruity will have a stronger correlation with brand loyalty than actual self-congruity.

\section{Methods}

For the purpose of this study, self-esteem is defined as how positively or negatively an individual feels about himself or herself [22]. Actual self-congruity is defined as perceived similarity between the product-user image and an individual's actual self-concept (who she believes herself actually to be). Ideal self-congruity is defined as perceived similarity between the product-user image and an individual's ideal self-concept (who she would like to be).

The selected apparel brands are Nike, Lululemon Athletica, Adidas, Puma, Under Armour and Athleta. These brands were chosen because Mintel [23] ranks them as the industry leaders.

\subsection{Data Collection}

To answer the research question, a survey questionnaire was created and distributed via Qualtrics, an online survey software. Participants were recruited via social media. On social media, links were posted on the researcher's social networking sites. A link was then been sent to the participants via email. Note: a web- based survey is appropriate for this research project because individuals in this age group are heavy users of social and digital media.

Each respondent was directed either to respond to the self-esteem section of the survey or to the brand loyalty and self-congruity section of the survey. After completing the first, she was directed to the second.

The self-esteem section consisted the Rosenberg self-esteem scale. The brand loyalty and self-congruity section of the survey began by asking the respondent to mark which of the selected brands she uses most frequently. She then filled out the brand loyalty inventory for that brand. Next, she was directed to think about the brand following Sirgy's cognitive elaboration prompt and was instructed to respond to the actual and ideal self-congruity items in randomized order. Finally, the survey asked for demographic information, including race, age and education level. 


\subsection{Samples and Characteristics}

Females between the ages of $18-24$ were targeted as participants for this survey. The survey screened respondents by asking for their age and gender, and quotas were used to ensure that 150 of the respondents were female and within 18 - 24 years of age. 277 individuals opened the survey, with 151 female respondents within the ages of $18-24$ who completed the survey.

The majority of respondents identified themselves as White $(\mathrm{n}=145,96.0 \%)$, and of these, 4 identified themselves as of Hispanic, Latin, or Spanish origin. The remainder identified themselves as American Indian or Alaska Native $(\mathrm{n}=4$, 2.6\%), Black, Afro-Caribbean, or African American ( $\mathrm{n}=3,2.0 \%)$, Asian American or East Asian ( $\mathrm{n}=2,1.3 \%)$, Middle Eastern or Arab American $(\mathrm{n}=2,1.3 \%)$, South Asian or Indian American ( $n=1,0.7 \%)$, or other $(n=1,0.7 \%)$.

The majority of respondents had completed some higher education $(\mathrm{n}=146$, 96.7\%). These respondents indicated that they had completed some undergraduate study $(\mathrm{n}=64,42.0 \%)$, an undergraduate degree $(\mathrm{n}=52,34.0 \%)$, some graduate study $(\mathrm{n}=20,13.2 \%)$, or a master's degree $(\mathrm{n}=10,6.6 \%)$. A smaller number of participants had completed only some high school $(\mathrm{n}=2,1.3 \%)$ or held only a high school degree $(n=3,2.0 \%)$.

Respondents indicated varying household income levels: below $\$ 20,000(\mathrm{n}=$ 40, 26.5\%), $\$ 20,000-\$ 29,999(\mathrm{n}=19,12.6 \%), \$ 30,000-\$ 39,999(\mathrm{n}=15,9.9 \%)$, $\$ 40,000-\$ 49,999(\mathrm{n}=14,9.3 \%), \$ 50,000-\$ 59,999(\mathrm{n}=11.7 .3 \%), \$ 60,000-$ $\$ 69,999(\mathrm{n}=8,5.3 \%), \$ 70,000-\$ 79,999(\mathrm{n}=7,4.6 \%), \$ 80,000-\$ 89,999(\mathrm{n}=10$, $6.6 \%)$, and $\$ 90,000$ or more $(\mathrm{n}=27,17.9 \%)$.

\subsection{Concepts and Measurements}

The global measure of self-congruity. The survey questionnaire evaluated self-congruity using Sirgy et al.'s [13] global measure of self-congruity. This measure is superior to other methods because it measures self-congruity directly and without predetermined traits, allows for high cognitive elaboration, and can be adapted to measure actual and ideal self-concepts independently.

\section{Impression Formation Processes}

Traditionally, researchers have studied self-congruity using a trait-by-trait analysis of both self-concept and product-user image, then comparing evaluations of brands to individuals' evaluations of their own self concepts by calculating a mathematical discrepancy [13]. For example, Dolich [10] used a series of semantic differentials to measure real self-concept, ideal self-concept and brand images. Heath and Scott [24] measured perceived brand user personality using a 24-item five-point scale. Hamilton and Sun [25] used a 15-item seven-point scale to measure self-image, ideal brand-image and perceived brand image.

Some support exists for this comparison method [26]; however, trait-by-trait analysis also has its detractors. Sirgy et al. [13] argue that consumers view brands holistically, rather than as a series of individual traits. The researchers also note 
that eliciting responses to a set of predetermined traits may not be a valid approach because it asks subjects to indicate their perceived congruity with traits they may not associate with the brand at all. Finally, asking subjects about their brand perceptions and self-perceptions independently of each other does not directly capture their feelings of congruity or incongruity toward the brand.

To capture the gestalt effect of brand image, Sirgy et al. [13] proposed a direct, global measure of self-congruity. The researchers asked respondents to rate self-congruence directly by indicating agreement or disagreement on a Likert scale with statements such as "This [product $\mathrm{x}$ ] is consistent with how I see myself" (p. 232). In a series of six studies comparing the new method of measuring self-congruity to trait-by-trait analysis, Sirgy et al. [13] found that the global method had higher predictive validity of various behaviors including brand preference, product form preference, brand attitude, program choice and consumer satisfaction.

Aguirre-Rodriguez et al.'s [2] ambitious meta-analysis of more than 100 articles provides support for this. The researchers examined various studies' impression formation processes (which refers to how each study asks consumers to evaluate self-congruity). They distinguished between studies using a trait-by-trait evaluation (ex. "[This brand] is [trait].") and those attempting to elicit a "big picture" impression (ex. "I am like [this brand]."). The researchers found that a holistic, or global, approach, such as the one recommended by Sirgy et al. [13] elicits a stronger self-congruity effect.

Cognitive elaboration. Cognitive elaboration refers to the degree to which a study asks consumers to think about their responses to questions about self-congruity. Some studies ask for quick judgments (simply asking the respondent to rate associated traits or congruence with the brand) while others encourage a longer thought process (by asking the respondent to envision a scenario rating associated traits or congruence with the brand) [2].

Sirgy et al. [13] recommend a high cognitive elaboration technique. The researchers advise instructing respondents first to contemplate the product, then imagine the kind of person who uses the product and apply adjectives to this typical user before finally indicating the degree to the product is consistent with how respondents see themselves. The study gives this example:

"Take a moment to think about [product $\mathrm{x}$ ]. Think about the kind of person who typically uses [product $\mathrm{x}$ ]. Imagine this person in your mind and then describe this person using one or more personal adjectives such as, stylish, classy, masculine, sexy, old, athletic or whatever personal adjectives you can use to describe the typical user of [product $\mathrm{x}$ ]. Once you've done this, indicate your agreement or disagreement to the following statement: This [product $\mathrm{x}$ ] is consistent with how I see myself [in situation y]."

Aguirre-Rodriguez et al.'s [2] meta-analysis supports such high cognitive elaboration techniques. The researchers found that studies that employed high cognitive elaboration showed stronger self-congruity effects than those that used low cognitive elaboration. 
Self-concept dimensions. The present research seeks to determine how self-esteem moderates the influences of actual self-concept and the ideal self-concept [14]. Drawing on Malar et al.'s [5] study, these motives can be measured using an adapted version of Sirgy et al.'s [13] global approach with high cognitive elaboration using prompts as follows:

Think about [brand $\mathrm{x}$ ]. Think about the kind of person who typically uses [brand $\mathrm{x}$ ]. Imagine this person in your mind and then describe this person using one or more adjectives. Once you've done this, indicate your agreement with the following statements:

1) The personality of the user of this brand is consistent with how I see myself (my actual self).

2) This user of this brand is a mirror image of me (my actual self).

3) This personality of the user of this brand is consistent with how I would like to be (my ideal self).

4) This user of this brand is a mirror image of the person I would like to be (my ideal self).

Measures of brand loyalty. Brand loyalty is one of the most common cognitive measures used to predict consumer behavior toward a brand [8]. Whereas brand attachment measures only a customer's emotional bond and feelings toward a brand [5], brand loyalty is a "deeply held commitment to rebuy or repatronize a preferred product/service consistently in the future, thereby causing repetitive same-brand or same brand-set purchasing." Some researchers have focused on attitudinal measures of brand loyalty (planned purchase or word-of-mouth commitment), and others have focused on behavioral measures (share of wallet, percentage of brand purchases, and/or repurchase behavior) [1].

Liu-Tompkins and Tam [27] argue that research should consider both attitudinal and behavioral measures. They cite Oliver's [28] assertion that attitudinal measures of brand loyalty precede and contribute to behavioral measures. The researchers measured brand loyalty using a seven-point Likert scale for each of the following items: 1) "I like [this brand] more than other [brands in the same product category]," 2) "I have a strong preference for [this brand]," 3) I give first consideration to [this brand] when I need to buy [items in this product category]," and 4) "I would recommend [this brand] to others." They measured behavioral measures by asking consumers about their purchasing habits.

As a further measure of consumer behavior regarding the selected brands, the survey will include one item that asks about brand use. The item will ask respondents to answer on a scale from 1 - 7 how frequently they use each brand in the study. Their use of the brand they select as most likely to prefer will be recorded as the variable "BrandUse."

Measures of self-esteem. Self-esteem can be defined as how positively or negatively an individual feels about himself or herself [22]. It is not the same as one's self-concept but rather the positive or negative evaluation of that self-concept. Consumer self-esteem is relevant in studies of persuasion efforts. 
Malär et al. [5] noted its relation to the effect of self-congruity motives on brand attachment. Researchers believe individuals with high self-esteem are less easily persuaded than individuals with low self-esteem [6], and Zeidmen [7] found that participants with low self-esteem were more likely to be persuaded by high fear messages.

The Rosenberg Self-Esteem Scale [29] is the most commonly used measure of self-esteem [29]. It is a 10-item Likert-type scale including the following statements:

1) I feel that I am a person of worth, at least on an equal plane with others.

2) I feel that I have a number of good qualities.

3) All in all, I am inclined to feel that I am a failure.

4) I am able to do things as well as most other people.

5) I feel I do not have much to be proud of.

6) I take a positive attitude toward myself.

7) On the whole, I am satisfied with myself.

8) I wish I could have more respect for myself.

9) I certainly feel useless at times.

10) At times I think I am no good at all.

Items 3, 5, 8, 9 and 10 are reversed, and a mean score is calculated. A higher score represents high self-esteem (a positive evaluation of oneself) and a lower score represents low self-esteem (a negative evaluation of oneself).

\subsection{Reliability of Scales}

Brand loyalty, actual self-congruity, ideal self-congruity, and self-esteem were all measured using summated scales. A test of reliability was performed for each scale.

Four items were used to measure the concept of brand loyalty. These four items formed a new variable titled, "BLoyalty." Internal consistency for these items was analyzed using Cronbach's alpha. The alpha was 0.868 .

Two items were used to measure the concept of actual self-congruity. These two items formed a new variable titled, "ASC." Internal consistency for these items was analyzed using Cronbach's alpha. The alpha was 0.879 .

Two items were used to measure the concept of ideal self-congruity. These two items formed a new variable titled, "ISC." Internal consistency for these items was analyzed using Cronbach's alpha. The alpha was 0.788 .

Ten items were used to measure the concept of ideal self-congruity. These ten items formed a new variable titled, "SEsteem." Internal consistency for these items was analyzed using Cronbach's alpha. The alpha was 0.858 .

Because only one item was used to measure use of preferred brand, a Cronbach's alpha was not calculated for this concept.

\section{Results}

SPSS was used to model the structural relationship suggested by the conceptual 
framework. To test $\mathrm{H} 1$ and $\mathrm{H} 2$, a regression model was used to calculate the extent to which actual self-congruence and ideal self-congruence predicted brand loyalty. The hypothesis is that actual self-congruence and ideal self-congruence will both be positively correlated with brand loyalty.

To test H3, a moderation analysis was used to calculate how self-esteem moderates actual self-congruity and ideal self-congruity's effects on brand loyalty. The hypothesis is that low self-esteem will increase ideal self-congruity's effect on brand loyalty and high self-esteem will increase actual self-congruity's effect on brand loyalty.

H1 stated actual self-congruity will be positively correlated with brand loyalty. A Pearson correlation coefficient was calculated for the relationship between actual self-congruity and brand loyalty. A strong positive correlation was found, $(\mathrm{r}(151)=0.323, \mathrm{p}<0.001)$, indicating a significant linear relationship between the two variables.

H2 stated ideal self-congruity will be positively correlated with brand loyalty. A Pearson correlation coefficient was calculated for the relationship between ideal self-congruity and brand loyalty. A strong positive correlation was found ( $\mathrm{r}$ $(151)=0.401, \mathrm{p}<0.001)$, indicating a significant linear relationship between the two variables.

$\mathrm{H} 3 \mathrm{a}$ and $\mathrm{H} 3 \mathrm{~b}$ examined the degree to which self-esteem moderated the relationships between actual self-congruity and brand loyalty and between ideal self-congruity and brand loyalty. To test $\mathrm{H} 3 \mathrm{a}$ and H3b, I assessed interaction effects for self-esteem using Hayes' PROCESS macro in SPSS. Self-esteem and the independent variable (actual or ideal self-congruity) were entered into an ordinary least-squares regression model to test their effects on brand loyalty. In both cases, the overall regression models were significant, but no significant interaction was found.

A significant regression equation was found to predict respondents' brand loyalty based on their actual self-congruity $(F(3,147)=5.9327, \mathrm{p}<0.001)$. Respondents' predicted brand loyalty is equal to $4.575-0.0916$ (Self-Esteem) + 0.0942 (Actual Self-Congruity) +0.0465 (Self-Esteem $\times$ Actual Self-Congruity) However, no significant interaction effect was found $(B=0.0465, p>0.05)$. Self-esteem does not significantly moderate the relationship between actual self-congruity and brand loyalty. H3a was not supported. See Table 1.

A significant regression equation was found to predict respondents' brand

Table 1. Summary of Moderation Analysis for Interaction of Self-Esteem on the Relationship between Actual Self-Congruity and Brand Loyalty $(\mathrm{N}=151)$.

\begin{tabular}{ccccc}
\hline Variable & $\mathrm{B}$ & $\mathrm{SE}(\mathrm{B})$ & $\mathrm{t}$ & Sig. $(\mathrm{p})$ \\
\hline Self-Esteem & -0.0916 & 0.2549 & -0.3594 & 0.7198 \\
Actual Self-Congruity & 0.0942 & 0.4172 & 0.2257 & 0.8218 \\
Interaction & 0.0465 & 0.0738 & 0.6297 & 0.5298
\end{tabular}

Note: $\mathrm{R}=0.3286, \mathrm{R}^{2}=0.1080$ 
loyalty based on their ideal self-congruity $(\mathrm{F}(3,147)=10.1423, \mathrm{p}<0.001)$. Respondents' predicted brand loyalty is equal to $4.494+0.0588$ (Self-Esteem) + 0.2394 (Ideal Self-Congruity) +0.0200 (Self-Esteem $\times$ Ideal Self-Congruity) However, no significant interaction effect was found $(B=0.0200, p>0.05)$. Self-esteem does not significantly moderate the relationship between ideal self-congruity and brand loyalty. H3b was not supported. See Table 2.

To further examine the relationships between actual and ideal self-congruity and brand loyalty, a multiple regression analysis was performed. A significant regression model was found to predict respondent's brand loyalty based on both their actual self-congruity and their ideal self-congruity $(\mathrm{F}(2,148)=15.683, \mathrm{p}<$ $0.001)$; however, only ideal self-congruity was a significant predictor $(\mathrm{p}<0.05)$. Respondents' predicted brand loyalty is equal to $3.622+0.143$ (Actual SelfCongruity) +0.321 (Ideal Self-Congruity). See Table 3 .

To further examine the relationships between actual and ideal self-congruity and use of preferred brand, a multiple regression analysis was performed. A significant regression model was found to predict respondent's use of preferred brand based on both their actual self-congruity and their ideal self-congruity ( $F$ $(2,148)=9.959, \mathrm{p}<0.001)$; however, only actual self-congruity was a significant predictor $(\mathrm{p}<0.05)$. Respondents' predicted use of preferred brand is equal to $3.234+0.223$ (Actual Self-Congruity) +0.166 (Ideal Self-Congruity). See Table 4.

Table 2. Summary of Moderation Analysis for Interaction of Self-Esteem on the Relationship between Ideal Self-Congruity and Brand Loyalty $(\mathrm{N}=151)$.

\begin{tabular}{ccccc}
\hline Variable & $\mathrm{B}$ & $\mathrm{SE}(\mathrm{B})$ & $\mathrm{t}$ & Sig. $(\mathrm{p})$ \\
\hline Self-Esteem & 0.0588 & 1.5157 & 2.3054 & 0.0225 \\
Ideal Self-Congruity & 0.2394 & 0.2635 & 0.2229 & 0.8239 \\
Interaction & 0.0200 & 0.3416 & 0.7009 & 0.4845 \\
\hline
\end{tabular}

Note: $R=0.4141, R^{2}=0.1715$.

Table 3. Summary of Multiple Regression Analysis for Actual and Ideal Self-Congruity Predicting Brand Loyalty $(\mathrm{N}=151)$.

\begin{tabular}{cccccc}
\hline Variable & $\mathrm{B}$ & Std. Error & $\beta$ & $\mathrm{t}$ & Sig. (p) \\
\hline Actual Self-Congruity & 0.157 & 0.099 & 0.143 & 1.590 & 0.114 \\
Ideal Self-Congruity & 0.273 & 0.077 & 0.321 & 3.564 & 0.000 \\
\hline
\end{tabular}

Note: $\mathrm{R}=0.418, \mathrm{R}^{2}=0.175$

Table 4. Summary of Multiple Regression Analysis for Actual and Ideal Self-Congruity Predicting Use of Preferred Brand ( $=151)$.

\begin{tabular}{cccccc}
\hline Variable & $\mathrm{B}$ & Std. Error & $\beta$ & $\mathrm{t}$ & Sig. $(\mathrm{p})$ \\
\hline Actual Self-Congruity & 0.3330 & 0.138 & 0.223 & 2.393 & 0.018 \\
Ideal Self-Congruity & 0.191 & 0.107 & 0.166 & 1.786 & 0.076 \\
\hline
\end{tabular}

Note: $R=0.344, R^{2}=0.119$. 
Table 5. Summary of Multiple Regression Analysis for Actual and Ideal Self-Congruity and Self-Esteem Predicting Use of Preferred Brand $(\mathrm{N}=151)$.

\begin{tabular}{cccccc}
\hline Variable & $\mathrm{B}$ & Std. Error & $\beta$ & $\mathrm{t}$ & Sig. (p) \\
\hline Actual Self-Congruity & 0.280 & 0.136 & 0.189 & 2.066 & 0.041 \\
Ideal Self-Congruity & 0.243 & 0.106 & 0.211 & 2.287 & 0.024 \\
Self-Esteem & 0.405 & 0.143 & 0.217 & 2.839 & 0.005 \\
\hline
\end{tabular}

Note: $\mathrm{R}=0.406, \mathrm{R}^{2}=0.164$.

To further examine the role of self-esteem in consumer preferences and behaviors, a Pearson correlation coefficient was calculated for the relationship between self-esteem and brand loyalty. No significant correlation was found ( $\mathrm{r}$ $(151)=0.051, p>0.05)$, indicating a significant linear relationship between the two variables. A Pearson correlation coefficient was also calculated for the relationship between self-esteem and use of preferred brand. A positive correlation was found $(\mathrm{r}(151)=0.199, \mathrm{p}<0.05)$, indicating a significant linear relationship between the two variables.

Additionally, a multiple regression analysis for actual and ideal self-congruity and self-esteem predicting use of preferred brand was conducted, and a significant regression model was found $(\mathrm{F}(3,147)=9.644, \mathrm{p}<0.001)$. All three independent variables were significant predictors of use of preferred brand, which is equal to $0.952+0.136$ (Actual Self-Congruity) +0.211 (Ideal Self-Congruity) + 0.217 (Self-Esteem). See Table 5.

\section{Discussion and Conclusion}

This research was intended to examine self-esteem's moderation of actual and ideal self-congruity on brand loyalty. Data analysis yielded the following findings:

1) Actual and ideal self-congruity are both positively correlated with brand loyalty.

2) Actual and ideal self-congruity are both positively correlated with use of preferred brand.

3) Ideal self-congruity was a significant predictor of brand loyalty; however, actual-self congruity was not.

4) Actual self-congruity was a significant predictor of use of preferred brand; however, ideal self-congruity was not.

5) Self-esteem did not significantly moderate the relationship between actual self-congruity and brand loyalty or ideal self-congruity and brand loyalty.

6) Self-esteem was positively correlated with and was a significant predictor of use of preferred brand.

\subsection{Self-Congruity Effects}

Because actual and ideal self-congruity were both positively correlated with brand loyalty, $\mathrm{H} 1$ and $\mathrm{H} 2$ were supported. In addition, actual and ideal self-congruity were both positively correlated with use of preferred brands. 
These findings are all consistent with prior research findings that self-congruity has a positive effect on brand preference [20], brand attitude [21] and brand loyalty [1].

\subsection{Actual vs. Ideal Self-Congruity}

Aguirre-Rodriguez et al.'s meta-analysis of self-congruity studies [2] suggests that enhancement-type motives generally have a stronger effect on consumer behavior than consistency-type motives, but existing research suggests the strength of actual vs. ideal congruity effects depends on a number of factors, the outcome being measured, and the context in which the product is used.

For some consumers, actual self-congruity has a greater effect on purchases than ideal self-congruity [4], and for consumers with high self-esteem, high product involvement and/or high public self-consciousness, actual self-congruence had a stronger positive effect on emotional brand attachment [5].

Although this study's findings did not identify a moderator of ideal and actual self-congruity effects on brand loyalty, it does contribute to body of research on the differing influences of ideal and actual self-congruity. Although actual and ideal self-congruity were both positively correlated with both brand loyalty and use of preferred brand, only ideal self-congruity was a significant predictor of brand loyalty, and only actual self-congruity was a significant predictor of brand use. This suggests that ideal and actual self-congruity are both important in consumer research but play distinct roles.

\subsection{The Role of Self-Esteem}

Malär et al. [5] demonstrated that high self-esteem strengthens the relationship between actual self-congruity and emotional brand attachment. Thus, H3a predicted that for participants with high self-esteem, actual self-congruity will have a stronger correlation with brand loyalty than ideal self-congruity, and H3b predicted that for participants with low self-esteem, ideal self-congruity will have a stronger correlation with brand loyalty than actual self-congruity.

However, neither H3a nor H3b was supported by the results. Although a significant regression model was found for each hypothesis, no significant interaction was found. Self-esteem was not shown to moderate actual or ideal self-congruity effects on brand loyalty.

One reason for not demonstrating a significant interaction could be consumers' varying levels of product involvement with fitness apparel and of public self-consciousness. Malär et al. [5] found that for consumers with high product involvement or high public self-consciousness, actual self-congruence had a stronger positive effect on emotional brand attachment. Thus, product involvement or public self-consciousness may have been a confounding variable.

Another reason for not demonstrating a significant interaction could be that this study only examined one product category. Graeff [17] found that ideal selfcongruity is more highly correlated than actual self-congruity to brand evalua- 
tions of publicly-consumed brands. Since fitness apparel is generally a publicly-consumed product category, this may have meant that ideal self-congruity had a greater effect overall, which may have concealed self-esteem's moderating effects.

Nonetheless, self-esteem did play a role in consumer behavior. It was positively correlated with and was a significant predictor of use of preferred brand. Participants with higher self-esteem were more likely to use their preferred fitness apparel brand frequently.

\subsection{Limitations}

This research had some limitations for several reasons. First, a convenience sampling method was used, and the research focused only on females ages 18 24. Majority of these respondents were white and held at least some college education. This does not well represent the general population. Thus, the results cannot be extrapolated to a general audience. Additionally, the survey asked about a limited number of brands and focused only on fitness apparel.

\subsection{Future Research}

Future research might examine self-esteem's moderation of actual and ideal selfcongruity effects more accurately by accounting for some of the possible confounding variables. Given Malär et al.'s [5] finding that high product involvement increases the effect of actual self-congruence on emotional brand attachment, researchers might replicate this study but limit the population to respondents who indicate high product involvement. Or to control for the effects of public and private consumption, researchers could replicate the study with several product categories and include both publicly-consumed and private-consumed items [17].

The finding that self-esteem is a significant predictor of use of preferred brand suggests further research into the role of self-esteem in consumer decision-making. An interesting direction for researching self-esteem would be to examine how positive self-esteem messages influence ideal and actual self-congruity effects on brand loyalty, brand preference, or brand emotional attachment.

Researchers could answer this question with a survey experiment that assigns respondents randomly to one of two conditions: advertisements with or without positive self-esteem messages. The survey would first ask respondents about their actual and ideal self-congruity with each brand, then expose them to the advertisements in their respective conditions, and finally ask them to fill out a brand loyalty, brand preference, and/or brand emotional attachment inventory. A moderation analysis could then be conducted to determine whether or not self-esteem messages moderate the effects of actual and ideal self-congruity on these brand metrics.

\subsection{Conclusion}

The results of this study reaffirm self-congruity theory by demonstrating that 
actual and ideal self-congruity are positively correlated with brand use and brand loyalty, and the findings that ideal self-congruity significantly predicts brand loyalty but not brand use and that actual self-congruity significantly predicts brand use but not brand loyalty are of interest. Additionally, the findings that self-esteem significantly predicts use of preferred brand suggest self-esteem is an important consideration in consumer behavior research. Further research into the relative importance of actual and ideal self-congruity and into self-esteem's impact would help researchers understand consumer motivations.

\section{References}

[1] Kressmann, F., Sirgy, M.J., Herrmann, A., Huber, F., Huber, S. and Lee, D. (2006) Direct and Indirect Effects of Self-Image Congruence on Brand Loyalty. Journal of Business Research, 59, 955. https://doi.org/10.1016/j.jbusres.2006.06.001

[2] Aguirre-Rodriguez, A., Bosnjak, M. and Sirgy, M.J. (2012) Moderators of the Self-Congruity Effect on Consumer Decision-Making: A Meta-Analysis. Journal of Business Research, 65, 1179. https://doi.org/10.1016/j.jbusres.2011.07.031

[3] Helgeson, J.G. and Supphellen, M. (2004) A Conceptual and Measurement Comparison of Self-Congruity and Brand Personality: The Impact of Socially Desirable Responding. International Journal of Market Research, 46, 205-233.

[4] Landon, E. (1974) Self Concept, Ideal Self Concept, and Consumer Purchase Intentions. Journal of Consumer Research, 1, 44-51. https://doi.org/10.1086/208590

[5] Malär, L., Krohmer, H., Hoyer, W. and Nyffenegger, B. (2011) Emotional Brand Attachment and Brand Personality: The Relative Importance of the Actual and the Ideal Self. Journal of Marketing, 75, 35-52. https://doi.org/10.1509/jmkg.75.4.35

[6] Bearden, W.O., Hardesty, D.M. and Rose, R.L. (2001) Consumer Self-Confidence: Refinements in Conceptualization and Measurement. Journal of Consumer Research, 28, 121-134. https://doi.org/10.1086/321951

[7] Zeidman, J. (2000) Self-Esteem and Persuasion: A Test of the Curvilinear Hypothesis. Journal of the Northwest Communication Association, 2979-2990.

[8] Fang, L., Li, J., Mizerski, D. and Huangting, S. (2012) Self-Congruity, brand attitude, and Brand Loyalty: A Study on Luxury Brands. European Journal of Marketing, 46, 922-937. https://doi.org/10.1108/03090561211230098

[9] Govers, P.M. and Schoormans, J.L. (2005) Product Personality and Its Influence on Consumer Preference. Journal of Consumer Marketing, 22, 189-197. https://doi.org/10.1108/07363760510605308

[10] Dolich, I.J. (1969) Congruence Relationships between Self Images and Product Brands. Journal of Marketing Research, 6, 80. https://doi.org/10.2307/3150001

[11] Birdwell, A.E. (1968) A Study of the Influence of Image Congruence on Consumer Choice. The Journal of Business, 41, 76-88. https://doi.org/10.1086/295047

[12] Sirgy, M.J. (1986) Self-Congruity: Toward a Theory of Personality and Cybernetics. Praeger Publishers/Greenwood Publishing Group.

[13] Missing Entry for Sirgy (1987).

[14] Sirgy, M. (1982) Self-Concept in Consumer Behavior: A Critical Review. Journal of Consumer Research, 9, 287-300. https://doi.org/10.1086/208924

[15] Aaker, J.L. (1999) The Malleable Self: The Role of Self-Expression in Persuasion. Journal of Marketing Research, 36, 45-57. https://doi.org/10.2307/3151914 
[16] Ross, I. (1971) Self-Concept and Brand Preference. Journal of Business, 44, 38-50. https://doi.org/10.1086/295331

[17] Graeff, T.R. (1996) Image Congruence Effects on Product Evaluations: The Role of Self Monitoring and Public/Private Consumption. Psychology \& Marketing, 13, 481-499. https://doi.org/10.1002/(SICI)1520-6793(199608)13:5<481::AID-MAR3>3.0.CO;2-5

[18] Kwak, D.H. and Kang, J.H. (2008) The Effect of Self/Team Follower Image Congruence on Spectator Sport Consumption Behavior and Team Loyalty. International Journal of Sport and Health Science, 6, 135-144. https://doi.org/10.5432/ijshs.IJSHS20070288

[19] Sung, Y., Choi, S. and Tinkham, S.F. (2012) Brand-Situation Congruity: The Roles of Self-Construal and Brand Commitment. Psychology \& Marketing, 29, 941-955. https://doi.org/10.1002/mar.20576

[20] Branaghan, R.J. and Hildebrand, E.A. (2011) Brand Personality, Self-Congruity, and Preference: A Knowledge Structures Approach. Journal of Consumer Behaviour, 10, 304. https://doi.org/10.1002/cb.365

[21] Sirgy, M.J. and Johar, J.S. (1999) Toward an Integrated Model of Self-Congruity and Functional Congruity. European Advances in Consumer Research, 4, 252-256.

[22] Galanou, C., Galanakis, M., Alexopoulos, E. and Darviri, C. (2014) Rosenberg Self-Esteem Scale Greek Validation on Student Sample. Psychology, 5, 819-827. https://doi.org/10.4236/psych.2014.58093

[23] Mintel (2014) Fitness Clothing US October 2014. Mintel Academic Database.

[24] Heath, A. and Scott, D. (1998) The Self-Concept and Image Congruence Hypothesis: An Empirical Evaluation in the Motor Vehicle Market. European Journal of Marketing, 32, 1110-1123. https://doi.org/10.1108/03090569810243749

[25] Hamilton, M. and Sun, X. (2005) Actual Self and Ideal Brand Image: An Application of Self-Congruity to Brand Image Positioning. Conference Papers International Communication Association, 1-26.

[26] Barnard, N.R. and Ehrenberg, A.S.C. (1990) Robust Measures of Consumer Brand Beliefs. Journal of Marketing Research, 27, 477-487. https://doi.org/10.2307/3172632

[27] Liu-Thompkins, Y. and Tam, L. (2013) Not All Repeat Customers Are the Same: Designing Effective Cross-Selling Promotion on the Basis of Attitudinal Loyalty and Habit. Journal of Marketing, 77, 21-36. https://doi.org/10.1509/jm.11.0508

[28] Oliver, R.L. (1999) Whence Consumer Loyalty? Journal of Marketing, 63, 33-44. https://doi.org/10.2307/1252099

[29] Rosenberg, M. (1965) Society and the Adolescent Self-Image. Princeton University Press, Princeton. https://doi.org/10.1515/9781400876136 